Polymer Journal, Vol. 39, No. 10, pp. 1018-1024 (2007)

(C) 2007 The Society of Polymer Science, Japan

\title{
Cross-linking of Grafted Copolymer on Colloidal Silica and Introduction of Surface Amino Group
}

\author{
Ju-Hyung LeE, ${ }^{1}$ Bong-Soo KIM, ${ }^{1}$ Jang-Oo LeE, ${ }^{1, \dagger}$ Sousuke IMAOKA, ${ }^{2}$ and Kohji YoshinaGA ${ }^{2}$ \\ ${ }^{1}$ Division of Chemical Engineering, Pusan National University, \\ 30 Jangjeon-dong, Geumjeong-gu, Busan 609-735, Republic of Korea \\ ${ }^{2}$ Department of Applied Chemistry, Kyushu Institute of Technology, \\ 1-1 Sensui-cho, Tobata-ku, Kitakushu 804-8550, Japan
}

(Received May 23, 2007; Accepted June 26, 2007; Published August 7, 2007)

\begin{abstract}
To obtain polymer-modified silica $(550 \mathrm{~nm}$ diameter), trimethoxysilyl-terminated poly(glycidyl methacrylate-co-methyl methacrylate) with epoxy ring (to prevent the formation of carboxyl group) was successfully synthesized. Then, the cross-linking of the grafted copolymer on silica was made using ethylenediamine or hexamethylenediamine of varying alkyl chain lengths, and the stability of cross-linked silica particles was investigated in alkaline aqueous solution. Cross-linked polymer-modified silica based on diamines exhibited much lower reduction rate (in wt $\%$ ) of the attached polymer to silica than uncross-linked polymer-modified silica. In particular, cross-linked silica composites by ethylenediamine had more stability than cross-linked silica composites by hexamethylenediamine. Finally, the cross-linking reaction of grafted-polymer on silica particles by diamines was confirmed by the ${ }^{13} \mathrm{C} \mathrm{CP} /$ MAS NMR spectra measured on polymer-modified silica composites. [doi:10.1295/polymj.PJ2007053] KEY WORDS Polymer-grafted Silica / Poly(glycidyl methacrylate-co-methyl methacrylate) Silane / Cross-linking / Surface Amino Group /
\end{abstract}

Polymer/inorganic composite materials are used in various industries for these materials complement each other, due to the excellent properties derived from polymer and inorganic material. ${ }^{1}$ Polymer/inorganic composite particle is one type of these materials widely used. The unique shape of the particles allows them to be used in various fields such as medical, coating and agents employed in plastic modification. ${ }^{2}$ Recently, monodispersed colloidal particles have received great attention for applications to composite materials. ${ }^{3-5}$ It is possible to attain a new kind of functional materials by using polymer silane on the surface of the inorganic colloidal particle through covalent bonding. ${ }^{6-8}$ Chemical modification on the surface of inorganic particles has been employed to improve dispersibility and compatibility in organic solvent, thus providing a processing route that is different from sol-gel process for preparing organic-inorganic hybrid composites. ${ }^{9,10}$ Furthermore, when amino, carboxyl or hydroxyl groups got introduced to the surface of inorganic particles, dispersibility of inorganic composite particles, mainly silica, had been greatly increased. ${ }^{8,11}$ In this regard, modification methods on the surface of inorganic particle using polymeric silane coupler are convenient and useful..$^{8,11-13}$ In previous studies, we have studied polymer modification on silica using poly(maleic anhydride-co-styrene)-trimethoxysilane and have been functionalizing inorganic colloidal particles by polymer modification. ${ }^{9,11,14,15}$ Moreover, a successive reaction of the composite with diisocyanates brought about an efficient cross-linking of the surface polymer. ${ }^{14}$ Also, the graftings of poly(methyl methacrylate) as a secondary polymer to poly(maleic anhydride-co-styrene)-modified silica particles resulted in controlling the surface polarity. ${ }^{14}$ However, during the process of reaction with secondary polymer, carbonyl acid was produced following maleic anhydride and amino group reacting to each other, leading to alter $\mathrm{pH}$ value of the system. Therefore, the procedure usually gives the composite particles having a shortcoming for the stability in acidic or basic condition, because of hydrolysis cleavage of siloxane bonds ( $\mathrm{Si}-\mathrm{O}-\mathrm{Si}$ ) between the silica and the polymer.

In this paper, we have prepared the P(GMA-coMMA)/silica using copolymer silane with epoxy ring to prevent the formation of carboxyl group and crosslinked surface polymer of silica composite particles by diamines. Then, we investigated amount of amino group on the surface of polymer-modified silica and stability of silica composite particles in alkaline aqueous solution.

\section{EXPERIMENTAL}

\section{Materials}

Monodispersed colloidal silica in ethanol, containing $20 \mathrm{wt} \% \mathrm{SiO}_{2}$ of $550 \mathrm{~nm}$ diameter, was obtained from Catalysts and Chemicals Ind., Japan. The mono-

${ }^{\dagger}$ To whom correspondence should be addressed (Tel: +82-51-510-2404, Fax: +82-51-513-7720, E-mail: leejo@pusan.ac.kr). 


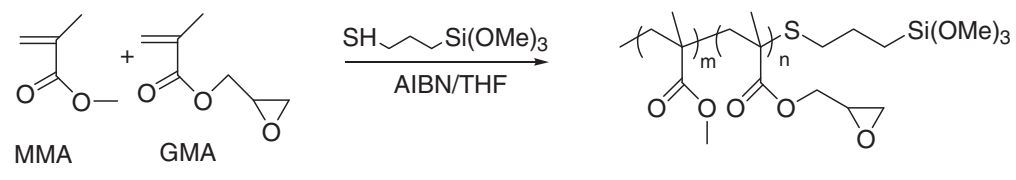

Scheme 1. Synthesis of copolymer silane of MMA and GMA.

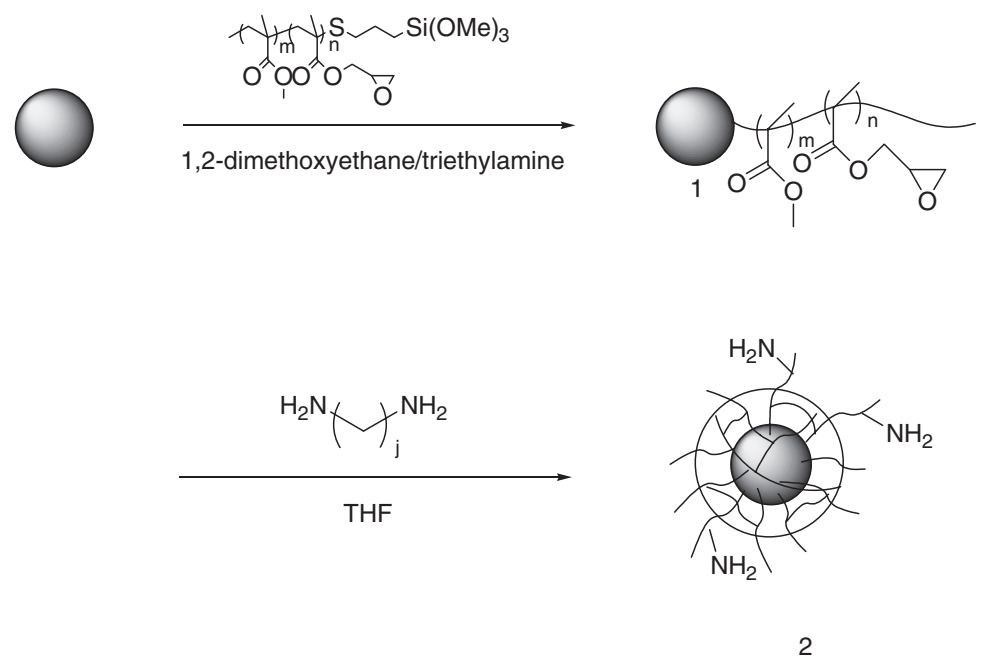

Scheme 2. Modification of colloidal silica by poly(glycidyl methacrylat-methyl methacrylate) and cross-linking by diamines.

mers and initiator used to synthesize copolymer silane were glycidyl methacrylate (GMA), methyl methacrylate (MMA) and 2, 2'-azobis(isobutyronitrile) (AIBN). They were obtained from Wako Pure Chemical Industries, Ltd., Japan and monomers were distilled under reduced pressure prior to use. Initiator was used after recrystallization from ethanol. 3mercaptopropyltrimethoxysilane, picric acid, triethylamine, ethylenediamine, hexamethylenediamine, boron trifluoride-diethyl etherate (Lewis acid) and N, N'diisopropylethylamine were purchased from Kanto Chemical Co., Japan and were used without further purification.

Synthesis of copolymer silane, P(GMA-co-MMA)$\mathrm{Si}(\mathrm{OMe})_{3}$

As shown in Scheme 1 to prepare trimethoxysilylterminated poly(glycidyl methacrylate-co-methyl methacrylate) [P(GMA-co-MMA)-Si(OMe $\left.)_{3}\right]$ used as a coupling agent for the synthesis of polymer-modified silica $\left[\mathrm{P}(\mathrm{GMA}-\mathrm{co}-\mathrm{MMA}) / \mathrm{SiO}_{2}\right]$, THF solution (3.56 g) containing GMA (4.06 g), MMA (3.00 g), 3mercaptopropyltrimethoxysilane $(0.21 \mathrm{~g})$ and AIBN $(1.30 \mathrm{mg})$ were stirred under refluxing for $7 \mathrm{~h}$ at $65^{\circ} \mathrm{C}$ in nitrogen atmosphere. The solution was poured into diethyl ether to precipitate a crude polymer. $\mathrm{P}(\mathrm{GMA}-\mathrm{co}-\mathrm{MMA})-\mathrm{Si}(\mathrm{OMe})_{3}$ with the number-average molecular weight $\left(\mathrm{M}_{\mathrm{n}}\right)$ of 5700 was obtained by precipitation from acetone solution with diethyl ether and drying under vacuum.
Preparation of polymer-grafted silica, P(GMA-co$\mathrm{MMA} / \mathrm{SiO}_{2}$

Scheme 2 shows that colloidal silica $\left(15 \mathrm{~cm}^{3}\right)$ was added to a mixture of $1 \mathrm{~g}$ P(GMA-co-MMA)$\mathrm{Si}(\mathrm{OMe})_{3}$ in $69.36 \mathrm{~g}$ 1,2-dimethoxyethane and $5.33 \mathrm{~g}$ THF. The suspension was vigorously stirred at $98^{\circ} \mathrm{C}$ and $69.36 \mathrm{~g}$ solvent was removed by azeotropic distillation. Then, the mixture was gently stirred under refluxing at $75^{\circ} \mathrm{C}$ for $12 \mathrm{~h}$ to obtain the polymer-modified silica. Unreacted copolymer silane was removed after centrifugal separation from the mixture in acetone five times and dried at room temperature under reduced pressure. $\mathrm{P}(\mathrm{GMA}-\mathrm{co}-\mathrm{MMA}) / \mathrm{SiO}_{2}$ was obtained. In order to confirm removal of the unreacted copolymer silane, the dried product was analyzed using ${ }^{1} \mathrm{H}-\mathrm{NMR}$ spectroscopy in $\mathrm{CDCl}_{3}$ as solvent. The attached polymer (A.P.), defined as the amount of polymer bound on silica per unit gram of $\mathrm{SiO}_{2}$, was determined by weight loss (mg) during temperature elevation from $100^{\circ} \mathrm{C}$ to $800^{\circ} \mathrm{C}$, after keeping the sample at $100{ }^{\circ} \mathrm{C}$ for $30 \mathrm{~min}$, according to previous studies. ${ }^{9}$

Cross-linking of grafted-polymer on silica by diamines

A suspension of $0.1 \mathrm{~g}$ composite 1 , as shown in Scheme 2, containing $0.11 \mathrm{~g}$ boron trifluoride-diethyl etherate (Lewis acid) and diamine in $2.67 \mathrm{~g}$ THF was stirred under refluxing for $8 \mathrm{~h}$ at room temperature in argon atmosphere. The resulting particles were 


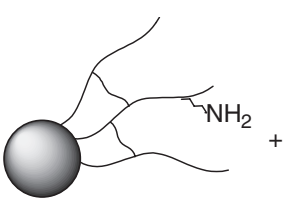

2

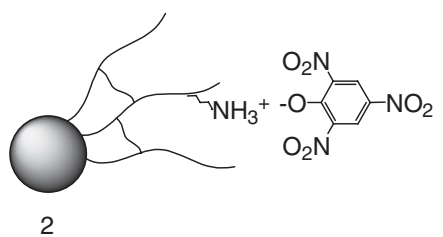$$
\text { (1) }
$$

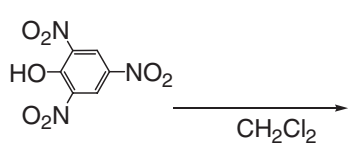

$\mathrm{CH}_{2} \mathrm{Cl}_{2}$

Scheme 3. Quantification of surface amino group.

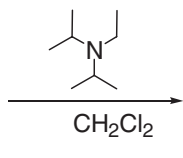

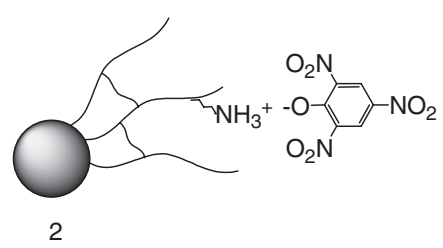

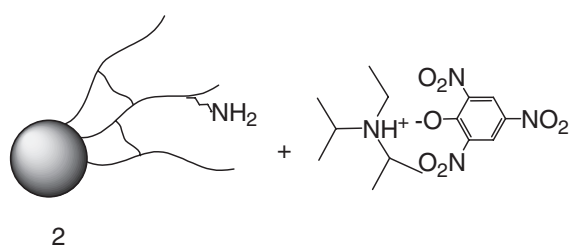

washed with $8.89 \mathrm{~g}$ THF five times in order to remove any unreacted polymer and $7.06 \mathrm{~g}$ diethyl ether by a centrifugation, and dried under vacuum to obtain composite 2. The confirmation of cross-linking on silica particles was estimated based on the difference between the amount of composite 1 and that of composite 2 .

\section{Determination of surface amino group on composite 2}

A typical run, shown in Scheme 3, was as follows. To the composite $2(20 \mathrm{mg})$ in ethanol, $0.1 \mathrm{M}$ picric acid ethanolic solution were added. The suspension was sonicated for $30 \mathrm{~min}$ and the resulting particles were obtained from $20 \mathrm{~cm}^{3}$ dichloromethane solution by centrifugation six times. The paste was dispersed in $5 \% \mathrm{~N}, \mathrm{~N}$-diisopropylethylamine dichloromethane solution by ultrasonic irradiation. The picrate anion on the composite 2 was transferred into the solution as $\mathrm{N}, \mathrm{N}$-diisopropylethylammonium picrate. A centrifugal separation of the picrate from the particles was repeated four times and the total volume of the solution was adjusted to $50 \mathrm{~cm}^{3}$ with dichloromethane. The surface amino group was measured by the concentration of picrate $(\varepsilon=14500$ at 358$)$ in the supernatant, which was obtained by a centrifugation.

Stability of cross-linked polymer-grafted silica, composite 2

Cross-linked polymer-grafted silica $(10 \mathrm{mg})$ was suspended in $3.96 \mathrm{~g}$ acetone solution, containing 0.6 $\mathrm{cm}^{3}$ triethylamine and $0.6 \mathrm{~cm}^{3} \mathrm{H}_{2} \mathrm{O}$, under ultrasonic irradiation and the centrifuge tube was left at room temperature for $24 \mathrm{~h}$ in order to investigate the stability of composite by observing the decreasing (or reduction) rate (in wt \%) of attached polymer (A.P.). After removal of residue with a centrifugation from acetone solution, the decrease of attached polymer was determined by thermo-gravimetric analyses (TGA).

\section{Measurements}

The synthesized polymers and composites were characterized by ${ }^{1} \mathrm{H}-\mathrm{NMR}$ and Solid state ${ }^{13} \mathrm{C} \mathrm{CP} /$ MAS NMR spectroscopy on a JEOL-FX60 and a Bruker AVANCE-300 using a $7 \mathrm{~mm}$ probe instrument, respectively. The number-average molecular weight $\left(\mathrm{M}_{\mathrm{n}}\right)$ and polydispersity index (PDI) of copolymer silane were determined by gel permeation chromatography (GPC) using THF eluant on TSK gel-3000H, based on calibration with polystyrene (PS) standard. Thermo-gravimetric analyses (TGA) studies on the composites were performed on a Shimadzu TGA-50 over the temperature range $100-800^{\circ} \mathrm{C}$ at a heating rate of $20^{\circ} \mathrm{C} / \mathrm{min}$ under a nitrogen purge. The surface amino group on silica particles was measured by spectrophotometric absorption on a JASCO V-520S.

\section{RESULTS AND DISCUSSION}

The polymer-grafted silica was synthesized by the reaction of trimethoxysilyl-terminated P(GMA-coMMA) with the surface hydroxyl group of colloidal silica particles. The reaction using the alkoxysilane provides a stable covalent boning via the siloxane bond on silica. ${ }^{8-10}$ The copolymer silane was prepared from MMA and GMA via suspension polymerization in the presence of an initiator (AIBN) and a chain transfer reagent (3-mercaptopropyltrimethoxysilane). In this modification, azeotropical removal of methanol and water produced during the reaction gave an effective attachment of the bound polymer.

As shown in Figure 1, the ${ }^{1} \mathrm{H}-\mathrm{NMR}$ resonance peaks of copolymer silane synthesized by inputting GMA and MMA with mole ratio of $1 / 1,1 / 3$ and $1 / 8$ was shown $3.6 \mathrm{ppm}$ for a $\left(-\mathrm{OCH}_{3}\right), 3.8$ and $4.3 \mathrm{ppm}$ for $\mathrm{b}\left(-\mathrm{OCH}_{2}-\right)$ respectively, $3.2 \mathrm{ppm}$ for $\mathrm{c}(\mathrm{CH}$ of epoxy ring) and 2.65 and $2.85 \mathrm{ppm}$ for $\mathrm{d}\left(\mathrm{C}_{2}\right.$ of epoxy ring) respectively. The copolymer silane was considered being synthesized without ring-opening of the 

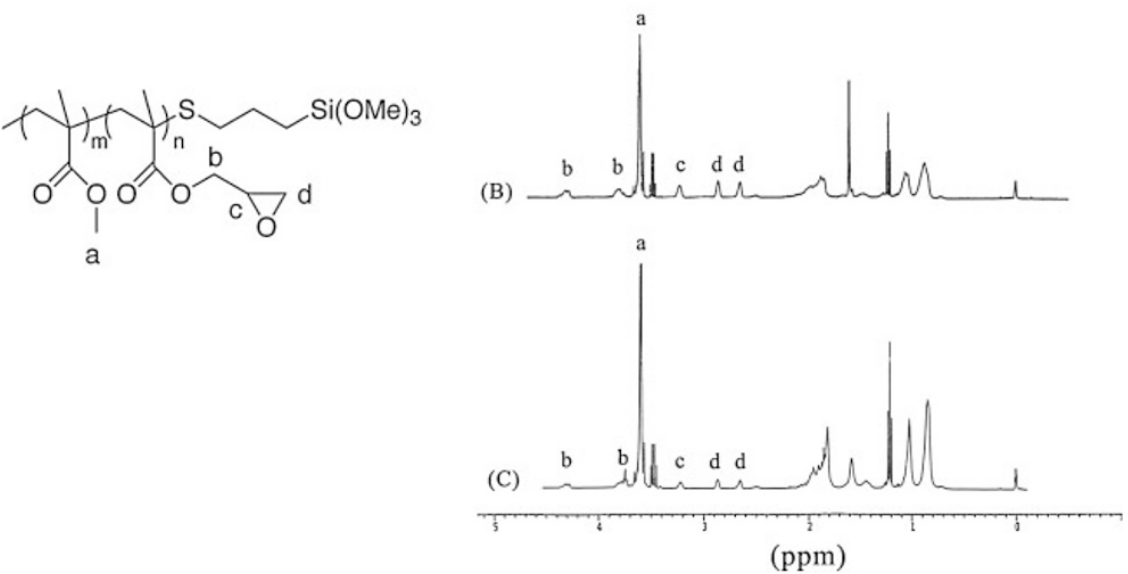

Figure 1. ${ }^{1} \mathrm{H}-\mathrm{NMR}$ spectra of poly(glycidyl methacrylat-co-methyl methacrylate)-trimethoxysilane with different mole ratios in the feed: (A) GMA and MMA of $1 / 1$; (B) $1 / 3$; and (C) $1 / 8$.

Table I. Characterization of poly(glycidyl methacrylateco-methyl methacrylate)-Si(OMe $)_{3}$

\begin{tabular}{cccc}
\hline GMA/MMA $^{\text {a) }}$ & $\begin{array}{c}\mathrm{M}_{\mathrm{n}} \text { of polymer } \\
\left(10^{-3}\right)\end{array}$ & $\mathrm{M}_{\mathrm{w}} / \mathrm{M}_{\mathrm{n}}$ & $\begin{array}{c}\text { Fraction in copolymer } \\
(\mathrm{n} / \mathrm{m})^{\mathrm{b})}\end{array}$ \\
\hline $1 / 1$ & 5.7 & 1.90 & $1 / 0.8$ \\
& 6.5 & 1.74 & $1 / 0.8$ \\
& 8.5 & 2.05 & $1 / 1$ \\
$1 / 3$ & 5.6 & 1.64 & $1 / 2$ \\
& 6.2 & 1.77 & $1 / 2.4$ \\
$1 / 8$ & 6.9 & 1.78 & $1 / 2.2$ \\
& 7.7 & 1.67 & $1 / 8$ \\
& 11.6 & 1.56 & $1 / 7.7$ \\
& 18.2 & 1.50 & $1 / 8.4$ \\
\hline
\end{tabular}

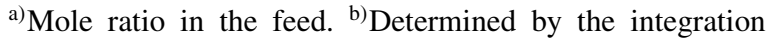
ratio of ${ }^{1} \mathrm{H}-\mathrm{NMR}$ spectra.

epoxy ring, for the integration ratio of peak b, c and $\mathrm{d}$ was at $1 / 1 / 1$ ratio disregarding the mole ratio in the feed. Also, integration ratio of a (MMA) and $d$ (GMA) was compared to analyze the mole ratio of GMA and MMA in the copolymer silane. Thus, the mole ratio of GMA and MMA in copolymer silane was found $1 / 0.87$ when mole ratio of $1 / 1$ solution was added, $1 / 2.2$ when $1 / 3$ mole ratio was added and $1 / 8.03$ when mole ratio of $1 / 8$ was added.

Table I shows characterization of poly(glycidyl methacrylate-co-methyl methacrylate)-trimethoxysilane. $M_{\mathrm{n}}$ increased with increasing MMA content in the feed. $M_{\mathrm{w}} / M_{\mathrm{n}}$ (PDI) of each copolymer silane was not related to the mole ratio of GMA and MMA in the feed.

Figure 2 illustrates the changes of the GMA mole

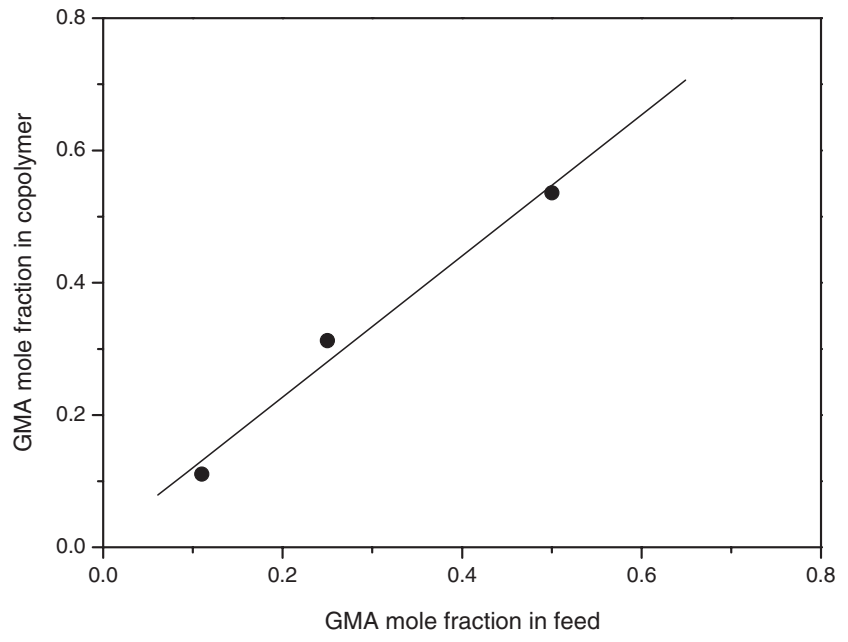

Figure 2. GMA mole fraction in copolymer silane versus GMA mole fraction in feed.

fraction between in feed and in copolymer silane characterized by ${ }^{1} \mathrm{H}$-NMR spectra. It is clear that the GMA mole fraction between in the feed and in the copolymer silane is nearly proportional. From this result, reaction rate of GMA and MMA can be judged to be similar to initial mole ratio in polymerization reaction.

When polymer chains on the surface of silica were not cross-linked, polymers on the surface of silica were separated in an acidic or alkaline atmosphere (Scheme 4). On the contrary, when polymer chains on the surface of silica were cross-linked, it is possible for polymers to be attached to silica particle by crosslinking network, even though $\mathrm{OH}^{-}$groups in alkaline solution break siloxane bonds. Therefore, we per- 

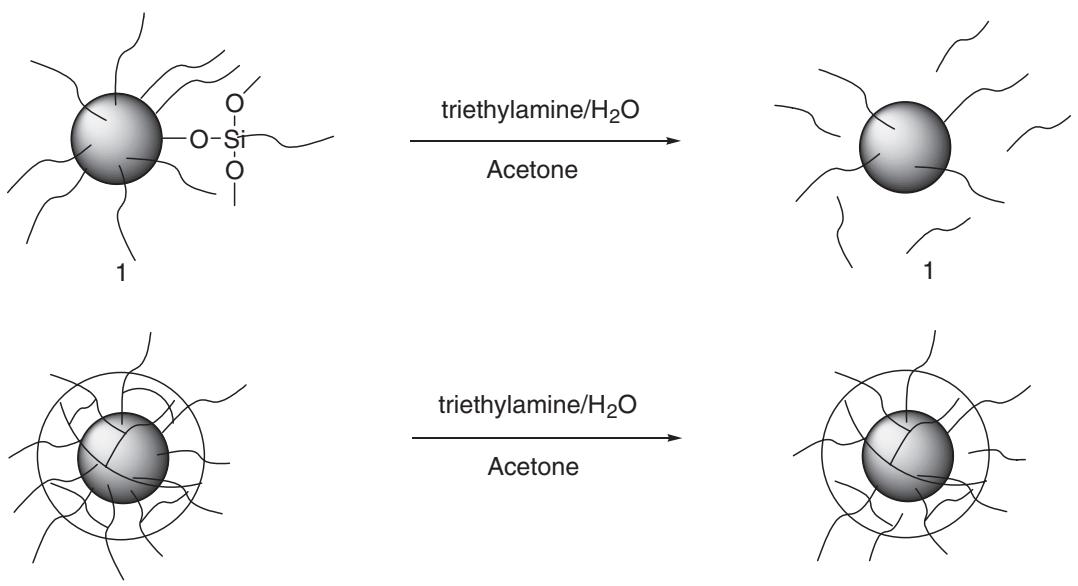

2

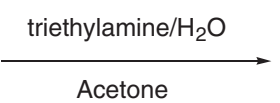

2

Scheme 4. Stability of cross-linked polymer-modified silica in alkaline aqueous solution.

Table II. Cross-linking of composite 1 by diamines

\begin{tabular}{lccccc}
\hline Cross-linker & Lewis acid $^{\mathrm{a}}$ & Solvent & GMA/MMA & $\begin{array}{c}\text { Diamine } \\
\left(\mathrm{mg} \cdot \mathrm{g}^{-1}\right)\end{array}$ & $\begin{array}{c}\Delta \text { A.P. } \\
\left(\mathrm{mg} \cdot \mathrm{g}^{-1}\right)^{\mathrm{b}}\end{array}$ \\
\hline $\begin{array}{c}\text { Hexamethylene- } \\
\text { diamine }\end{array}$ & None & THF & $1 / 1$ & 4.1 & 0 \\
& & & 18.0 & 0 \\
& & & 45.0 & 1.1 \\
& & & $1 / 3$ & 4.1 & 0 \\
& $\mathrm{BF}_{3} \cdot \mathrm{OEt}_{2}$ & Acetone & $1 / 1$ & 4.1 & 0.4 \\
& & THF & & 4.1 & 135.3 \\
& & $1 / 3$ & 2.5 & 125.4 \\
Ethylenediamine & & $1 / 8$ & 1.5 & 111.0 \\
& & & $1 / 1$ & 2.3 & 134.1 \\
& & $1 / 3$ & 1.3 & 124.3 \\
& & & 0.8 & 121.6 \\
\hline
\end{tabular}

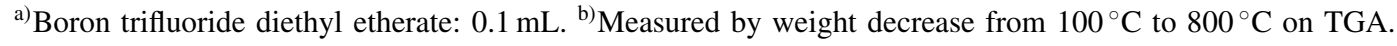

formed cross-linking surface polymer chains on silica by hexamethylenediamine or ethylenediamine and investigated the effect of cross-linking. In addition, any significant changes of particle size before and after cross-linking of surface grafted-copolymer on silica were not observed. As estimated from the assumption of freely-jointed chain, ${ }^{16}$ the (average) spreading size of grafted polymer chains was just $2-3 \mathrm{~nm}$. Hence, the increase of particle size by polymer grafting seemed to be quite small.

As shown in Table II, regardless of mole ratio of GMA and MMA in feed and hexamethylenediamine content, the amount of polymer bound on the surface of silica was not increased when the Lewis acid was not added. Hence, it was considered that ring-opening polymerization of epoxy ring with hexamethylenediamine did not occur. Moreover, the amount of attached polymer in acetone was not increased under Lewis acidic condition. However, the amount of attached polymer in THF solvent was increased approximately $100 \mathrm{mg}$ in existence of Lewis acid. It may be thought the cross-linking reaction was done. The increase of grafted-polymer was higher than that with reacted diamines entirely.

Figure 3 shows ${ }^{13} \mathrm{C} \mathrm{CP} / \mathrm{MAS}$ NMR spectra of composite 1 , composite 2 with ethylenediamine, and composite 2 with hexamethylenediamine. In these cases resonance peaks at $16 \mathrm{ppm}$ for $\mathrm{b}\left(\mathrm{CH}_{3}-\right), 45$ ppm for d $\left(\mathrm{H}_{2} \mathrm{CCCH}_{3} \mathrm{COCH}_{2}\right), 67 \mathrm{ppm}$ for e and $\mathrm{h}\left(-\mathrm{O}-\mathrm{CH}_{2} \mathrm{CH}_{2}-\right.$ and $\left.\mathrm{HO}-\underline{\mathrm{C}} \mathrm{H}-\right)$, and $177 \mathrm{ppm}$ for a $(-\mathrm{O}(\underline{\mathrm{C}}=\mathrm{O}) \mathrm{C}-)$ were observed. In Figure $3(\mathrm{~B})$ and (C) resonance peaks at $24 \mathrm{ppm}$ for $\mathrm{j}\left(\mathrm{H}_{2} \mathrm{~N}-\mathrm{CH}_{2} \mathrm{CH}_{2}\right.$ $\left.\mathrm{CH}_{2}-\right), 28 \mathrm{ppm}$ for i $\left(\mathrm{H}_{2} \mathrm{~N}_{-} \mathrm{CH}_{2} \mathrm{CH}_{2}-\right)$, and $52 \mathrm{ppm}$ for $\mathrm{g}\left(\mathrm{H}_{2} \mathrm{~N}-\mathrm{CH}_{2}-\right)$ were also observed. The resonance peak $\mathrm{f}$ at $49 \mathrm{ppm}$ was assignable to $\underline{\mathrm{C}} \mathrm{H}$ of epoxy ring. In Figure 3(B) and (C) the intensity of peak $f$ is weaker than that of (A). These results indicate that ring-opening of epoxy ring occurred by cross-linking reactions with diamines.

After composite 2 was prepared by cross-linking composite 1 with diamines, some useful informations were obtained from the measurement of amount of re- 


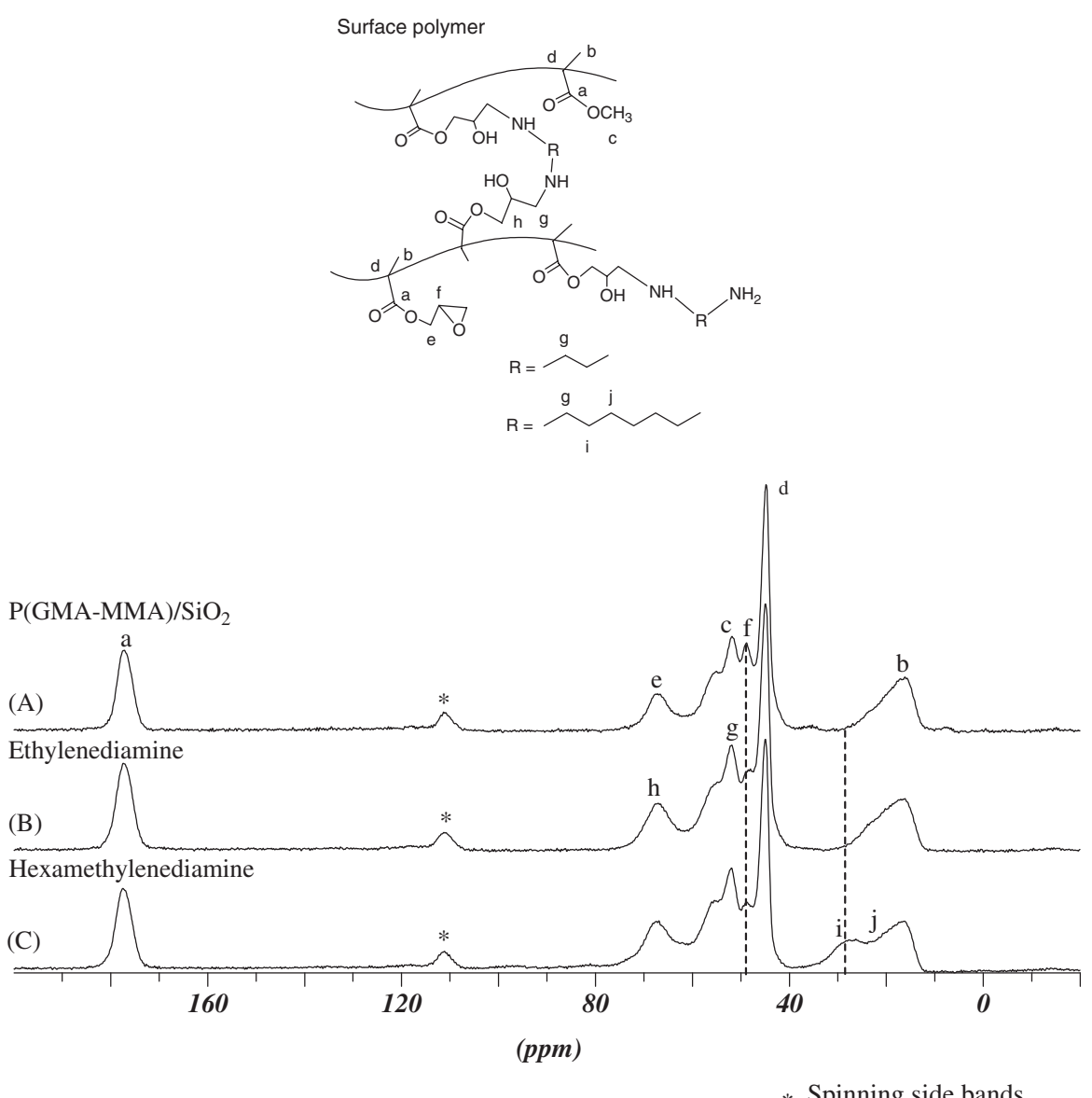

Figure 3. ${ }^{13} \mathrm{C} \mathrm{CP} / \mathrm{MAS}$ NMR spectra of composites 1 and 2: (A) composite 1; (B) composite 2 with ethylenediamine; and (C) composite 2 with hexamethylenediamine.

Table III. Amino groups on composite 2

\begin{tabular}{cccc}
\hline Cross-linker & GMA/MMA & $\begin{array}{c}\text { Diamine } \\
\left(\mu \mathrm{mol} \cdot \mathrm{g}^{-1}\right)^{\mathrm{b})}\end{array}$ & $\begin{array}{c}\mathrm{NH}_{2} \\
\left(\mu \mathrm{mol} \cdot \mathrm{g}^{-1}\right)\end{array}$ \\
\hline $\begin{array}{c}\text { Hexamethylenediamine } \\
\text { Ethylenediamine }\end{array}$ & $1 / 3$ & $21(125.4)$ & 7.7 \\
\hline
\end{tabular}

a) The values in parentheses denote amounts of bound poly(glycidyl methacrylate-co-methyl methacrylate) to silica.

sidual surface amino group on composite 2. As shown in Table III, amino group having 37\% amount of total hexamethylenediamine added and 29\% amount of total ethylenediamine added, was acquired in the existence of Lewis acid. 2/3 of input amino group was reacted to cross-linking of copolymer silane and ethylenediamine with short alkyl chain is more effective for the cross-linking of surface polymers on silica. From this quantitative result, regardless of amount of input hexamethylenediamine, the cross-linking reaction did not occur in the absence of Lewis acid, on the contrary, the cross-linking reaction occurred by activation of epoxy ring in the presence of Lewis acid.

As shown in Scheme 4, uncross-linked polymermodified silica was separated from polymer on the
Table IV. Stability test of composite 1 and $2^{\text {a) }}$

\begin{tabular}{ccc}
\hline Cross-linker & GMA/MMA & $\begin{array}{c}\text { Reduction of A.P. } \\
(\text { wt } \%)^{\text {b) }}\end{array}$ \\
\hline None & $1 / 1$ & 33.0 \\
& $1 / 3$ & 32.0 \\
Hexamethylenediamine & $1 / 8$ & 43.0 \\
Ethylenediamine & $1 / 1$ & 9.6 \\
& $1 / 3$ & 8.4 \\
& $1 / 8$ & 8.0 \\
& $1 / 1$ & 7.0 \\
& $1 / 3$ & 5.2 \\
\hline
\end{tabular}

a) After immersing composite 1 and 2 for $24 \mathrm{~h}$ in solvent of $\mathrm{Et}_{3} \mathrm{~N} / \mathrm{H}_{2} \mathrm{O} /$ acetone $(0.6 / 0.6 / 5 \mathrm{~mL})$. ${ }^{\text {b) }}$ Measured by TGA.

surface of silica in alkaline aqueous solution. However, cross-linked polymer-modified silica did not show occurrence of separation.

Table IV shows the results of stability of polymermodified silica in the alkaline aqueous solution. The reduction rate of polymer in the uncross-linked polymer-modified silica was from $30 \%$ to $45 \%$ approximately in the no relation with mole ratio of GMA 
and MMA in the feed. On the other hand, the reduction rate of polymer in cross-linked polymer-modified silica with ethylenediamine was $0-7 \%$. In the case of hexamethylenediamine, it was $8 \%$ to $10 \%$. Hence, the cross-linking reaction may occurred by diamines. Also, cross-linked silica composite with ethylenediamine is more stable composite in alkaline aqueous solution compared with hexamethylenediamine, simply from the fact that the reduction rate of polymer in polymer-modified silica exhibits much lower value when ethylenediamine was used.

\section{CONCLUSIONS}

To improve the stability of silica composite particles in acidic or alkaline aqueous solution, crosslinked polymer-modified silica particles were successfully prepared using diamines in the presence of Lewis acid. The copolymer silane, P(GMA-coMMA)-Si(OMe $)_{3}$, and the ring-opening of epoxy ring in copolymer between polymerization were confirmed by ${ }^{13} \mathrm{C} \mathrm{CP} / \mathrm{MAS}$ NMR spectra. In order to prepare cross-linked polymer-modified silica that is stable in alkaline aqueous solution, two diamines having different alkyl chains were used to perform cross-linking among copolymer chains on the surface of silica. The amount of surface amino group on silica was estimated by spectrophotometric absorption. Furthermore, the quantitative result of amino group existing on the surface of composite 2 and polymer reduction rate in alkaline aqueous solution exhibited that ethylenediamine having shorter alkyl chain is not only more effective for the cross-linking than hexamethylenediamine, but also more stable in alkaline aqueous solution.
Acknowledgment. This work was partially supported by the Brain Korea 21 Project.

\section{REFERENCES}

1. D. C. Lee and L. W. Jang, J. Appl. Polym. Sci., 61, 1117 (1996).

2. Y. Yang and Y. Dan, Colloid Polym. Sci., 281, 794 (2003).

3. A. R. Kortan, R. Hull, R. L. Opila, M. G. Bawendi, M. L. Steigerwald, P. J. Carroll, and L. E. Brus, J. Am. Chem. Soc., 112, 1327 (1990).

4. H. S. Zhou, I. Honma, H. Komiyama, and J. W. Haus, J. Phys. Chem., 97, 895 (1993).

5. S. Y. Chang, L. Liu, and S. A. Asher, J. Am. Chem. Soc., 116, 6739 (1994).

6. K. Yoshinaga, T. Yokoyama, Y. Sugawa, H. Karakawa, N. Enomoto, H. Nishida, and M. Komatsu, Polym. Bull., 28, 663 (1992).

7. K. Yoshinaga, T. Yokoyama, and T. Kito, Polym. Adv. Technol., 4, 38 (1993).

8. K. Yoshinaga and K. Nakanishi, Compos. Interfaces, 2, 95 (1994).

9. J. H. Lee, J. S. Im, K. W. Song, J. O. Lee, and K. Yoshinaga, J. Macromol. Sci., Pure Appl. Chem., A41, 1011 (2004).

10. J. S. Im, J. H. Lee, S. K. An, K. W. Song, N. J. Jo, J. O. Lee, and K. Yoshinaga, J. Appl. Polym. Sci., 100, 2053 (2006).

11. K. Yoshinaga, K. Nakanishi, Y. Hidaka, and H. Karakawa, Compos. Interfaces, 3, 231 (1995).

12. K. Yoshinaga, Bull. Chem. Soc. Jpn., 75, 2349 (2002).

13. K. Yoshinaga and Y. Hidaka, Polym. J., 26, 1070 (1994).

14. K. Yoshinaga and M. Teramoto, Bull. Chem. Soc. Jpn., 69, 2667 (1996).

15. K. Yoshinaga and T. Kobayashi, Colloid Polym. Sci., 275, 1115 (1997).

16. L. H. Sperling, in "Introduction to Physical Polymer Science," 2nd ed., John Wiley \& Sons, New York, 1992, chap. 5, p 173. 